\title{
Bystanders to Bullying: An Introduction to the Special Issue
}

\section{Angela Mazzone ${ }^{1}$}

Published online: 15 January 2020

(C) Springer Nature Switzerland AG 2020

\section{Bystander Behaviour in Different Contexts}

Researchers worldwide have investigated the phenomenon of bullying, which has been defined as aggressive, goal-oriented behaviour which harms another individual within the context of a power imbalance (Volk et al. 2014). With the rising of new technologies, bullying has been observed also in the online context. Cyberbullying is defined as "willful and repeated harm inflicted through computers, cell phones, and other electronic devices" (Hinduja and Patchin 2015; page 11). Bullying and cyberbullying are a cause of concern not only at school but also in other institutional contexts (e.g., College; workplace) (Bartlett and Bartlett 2011; Varghese and Pistole 2017). The forms and dynamics that these negative behaviours take in various settings are relatively similar (Monks et al. 2009).

Bullying has been described as a social phenomenon involving several onlookers or bystanders beyond the perpetrator and the target. Research investigating bullying at school has outlined that bystanders might show a constructive behaviour, such as helping the target and preventing any escalation of the situation, or they might reinforce bullying through their behaviour (Salmivalli et al. 1996). More specifically, some bystanders, referred to as assistants, take side with the perpetrator, by helping actively, while some others support the perpetrator indirectly, through laughing or smiling when bullying happens. These bystanders are referred to as reinforcers, because they are thought to reinforce bullying with their behaviours. Defenders help the target of bullying, either by supporting the target or by confronting the perpetrator. Finally, some bystanders, referred to as passive bystanders, avoid any involvement, and shy away when bullying happens (Salmivalli et al. 1996).

Angela Mazzone

angela.mazzone@dcu.ie

1 National Anti-Bullying Research and Resource Centre, Institute of Education, Dublin City University, Dublin, Ireland
The behaviour of passive bystanders has also been suggested to reinforce bullying (Kärnä et al. 2011). This is mainly because bystanders' passive behaviour can signal a silent assent to the perpetrators. Workplace bullying research has also recognised the role of bystanders as integral rather than incidental to the bullying episodes, and has shown that the bystander typologies are relatively similar to the ones identified in the school bullying research. More specifically, bystanders may take side with the target or with the perpetrator, and can even take multiple roles (Paull et al. 2012). The presence of bystander is widespread both at school and in the workplace. Naturalistic observation of bullying at school showed that bystanders are present in $88 \%$ of bullying episodes, but they intervene in 19\% of them (Lynn Hawkins et al. 2001). In the workplace, up to $30 \%$ of employees have experienced witnessing bullying (Ólafsson and Jóhannsdóttir 2004). High peer acceptance of passive bystander behaviour has been found also in the online context (i.e., about $76 \%$ of youngsters had been bystanders at least once) (Vandebosch and van Cleemput 2009).

Different variables seem to affect bystander behaviour. For instance, the presence of many bystanders - compared with the presence of a few bystanders - attenuates their sense of responsibility, and in turn actually discourages bystander intervention (Obermaier et al. 2016). In line with the model of bystander intervention (Latané and Darley 1970), bystanders are more willing to intervene when they perceive the incident as serious, when they interpret the situation as an emergency, and when there are no other onlookers. Importantly, being exposed to bullying can have serious implications on the mental health of bystanders (Rivers et al. 2009), which is one of the reasons why bystanders should be supported and equipped to recognise and tackle bullying.

Overall, research on bystanders of bullying in different contexts has considerably increased in recent years; however, many issues need to be clarified. For instance, our knowledge of the different strategies that bystanders adopt to support the target is still limited. In addition, research investigating simultaneously individual and contextual factors linked to bystander behaviour is lacking. Moreover, literature has shown that 
combining physiological and self-report measures might constitute a new avenue to understand bystander behaviour (Barhight et al. 2013); however, studies combining both methods are lacking. Finally, researchers need to gain a deeper understanding of the evidence-based strategies that positively affect bystander behaviour in different bullying contexts.

Moving on from these reflections, the contributions in this special issue have the common goal to shed light on bystander behaviour in various contexts (e.g., school; College, workplace; cyberspace). Overall, the six contributions bring new knowledge to the field, and offer useful insights for future research.

\section{Bystander Behaviour: the Contribution of Moral Disengagement, Empathy, and Contextual Variables}

Previous research has shown that children who defend their victimised peers online are prosocial and show high levels of empathy (Romera et al. 2019; Barlinska et al. 2018). Different instruments, including self-reports and peer nominations, have been adopted to assess cyber-defending. However, one of the limitations in the extant literature is that the different types of cyber-defending behaviours (e.g., comforting the victim versus confronting the perpetrator) have rarely been disentangled (Bastiaensens et al. 2014). In addition, previous research has considered cyber-defending behaviour as a unidimensional construct involving prosocial behaviour (Barlinska et al. 2018). However, most recent studies have shown that cyberdefending behaviour does not involve only prosocial behaviours (DeSmet et al. 2014; Machackova and Pfetsch 2016).

In order to shed light on the different types of cyberdefending behaviours, the contribution by Moxey and Bussey (2019) in this special issue, presents a questionnaire measuring different forms of defending, which was administered to a sample of ethnically diverse Australian adolescents. Coherently with the aforementioned line of research, this study) shows that defending behaviour is a multidimensional construct, as defenders can employ constructive strategies, such as consoling the target of cyberbullying, or destructive strategies, such as threatening the perpetrator. The study shows that aggressive cyber-defenders are also likely to be cyber-perpetrators. Interestingly, the authors found an association between aggressive cyber-defending and moral disengagement, showing the importance to address socio-moral aspects in future anti-bullying programming.

The contribution by Schultze-Krumbholz et al. (2019) in this special issue, expands the focus of investigation by taking into account simultaneously individual and contextual factors associated with cyber-defending and assisting behaviours. Findings show that higher levels of cognitive and affective empathy are associated with higher cyber-defending behaviour. As to pro-bullying behaviour, the authors found that cognitive and affective empathy are associated with lower levels of cyber-assisting behaviour. The authors conclude that both empathy components might be seen as inhibitory factors against actively supporting cyberbullying behaviour.

Among the contextual factors investigated in this study, the authors found that teacher support along with lack of safety problems positively predict cyber-defending behaviour. Contextual factors are also associated with assisting cyberbystander behaviour, which is more likely in classrooms where students perceive less positive peer interactions. Interestingly, the study shows that individual predictors account for more variance than class-level factors when examining cyber-bystander behaviour. One possible interpretation of this finding might be related with the cultural context in which the study was conducted, as individual factors might be more relevant than contextual factors in countries with an individualistic orientation, such as Germany. In other words, students showing cyber-defending and assisting might be inclined to show these behaviours based on their individual dispositions, and might rely less on contextual factors, such as school climate. An alternative interpretation might have to do with the nature of the behaviour investigated; i.e., individual factors might be particularly relevant in the context of cyberbullying, because this form of negative behaviour might not happen on the school grounds, and as such, might be less tied to contextual factors. Overall, this study has the merit of shedding light on the role of individual and contextual factors in connection with cyber-defending and assisting behaviours.

The important role of empathy in fostering positive bystander behaviours is outlined in the contribution by Rudnicki et al. (2019). The authors of this study investigate celebrity bashing, which is a specific form of online aggressive behaviour involving derogatory messages towards celebrities. The study combines physiological and self-report measures, and investigates the role of the neurophysiological substrate of empathy (i.e., the oxytocinergic system) in affecting bystanders' response to online celebrity bashing. The authors found that intranasal oxytocin administration reduces bystanders' self-reported acceptance of online celebrity bashing. The study shows that combining self-report and physiological measures could give an important insight into bystander responses to negative behaviours online. One of the main methodological strengths in this study is the adoption of a noninvasive and objective measure in assessing the neurophysiological correlates of bystander behaviour.

\section{How to Increase Active Bystander Behaviour?}

Successful intervention programs have shown that in order to foster positive bystander behaviour, students need to (a) increase their awareness of bullying, (b) learn new skills to act in appropriate ways in bullying situations, and (c) be encouraged 
to make use of their knowledge and skills in real-life situations (Kärnä et al. 2011).

The contribution by Doane et al. (2019) in this special issue, builds its rationale around the importance of increasing bystanders' awareness about the positive responses to cyberbullying incidents. More specifically, the authors of this study explored the effect of a video providing suggestions on positive responses to cyberbullying incidents, on college students' intentions to help. The findings show that students in the experimental group are more willing to help immediately after the video, compared with students in the control group. Students in the experimental group report higher scores on intentions to help at one-month follow-up, though the differences between the two groups are non-significant. Overall, the study shows that participating in an informative session about positive bystander behaviour can have a positive impact in the very short-term. However, the findings indicate that being exposed to the intervention in a single session might not have a long-term impact on bystander behaviour. Based on these findings, future intervention programs should be more intense and systematic.

Employing a similar methodology, the study by Dal Cason et al. (2020) in this special issue, adopted video-vignettes depicting workplace bullying episodes with a sample of college students. The authors tested the hypothesis of a positive association between bystander intervention in support of the target of bullying, and moral courage (operationalised as "acting correctly in the face of popular opposition, shame, scandal or discouragement"). Findings show that moral courage fostered bystander intervention in situations of workplace bullying, especially among participants who showed high levels of personal involvement (i.e., willingness to help the target) and engagement with the video-vignettes. The study can be included in the line of research that addresses morality to empower bystanders against bullying. Workplace bullying literature has started only recently to look at bystanders and to recognise their role in the bullying dynamics. Therefore, this work is an important contribution to the workplace bullying literature.

The last contribution included in this special issue presents the evaluation findings of an anti-bullying intervention program aimed at empowering bystanders to tackle bullying. As outlined in a previous literature review (Sivaraman et al. 2019), there is a need for more rigorously evaluated anti-bullying intervention programs in low-income countries. The contribution by Arënliu et al. (2019) meets this need by evaluating, through a rigorous methodology, a short and ultra-short version of the Viennese Social Competence Program (ViSC), in a low-income country (i.e., Kosovo). The ViSC program aims at empowering adolescents to recognise bullying, and to intervene in bullying situations, and it has been shown to be effective in reducing victimisation with students in a high-income country such as Austria (Yanagida et al. 2019).

Findings show that the ultra-short version of the program is effective in reducing physical victimisation. Previous research findings have shown that programs with higher intensity and longer duration are more effective in reducing bullying and victimisation (Ttofi and Farrington 2011). However, findings of this study seem to go in an unexpected direction, as the ultra-short version of the program (i.e., four program units) was more effective compared with the short version (i.e., six units). It might be that students were more engaged with the ultra-short version of the program, because of being less demanding. Hence, the brief duration should not be viewed as a synonym of poor quality. On the opposite, this methodology could be particularly useful in countries with low resources.

Importantly, previous evaluations of anti-bullying programs in middle- and low-income countries have shown no effect on the reduction of bullying and victimisation (Sivaraman et al. 2019). Therefore, findings of this study contribute to the extant literature in that they show that an ultrashort intervention program can, to some extent, reduce victimisation, in spite of the limited resources.

\section{Conclusions}

By acknowledging the important role that bystanders cover in bullying situations, the contributions in this special issue aimed at investigating bystander behaviour in various contexts (i.e., school; cyberspace; college; workplace). Overall, this special issue expands our knowledge and provide useful insights for evidence-based intervention programs. The work by Moxey and Bussey (2019) show that cyber-defending can take different forms, among which aggressive responses. Two contributions included in this special issue consistently show the key role of empathy in enhancing positive bystander behaviour in online bullying (Rudnicki et al. 2019) and restraining from probullying behaviours (Schultze-Krumbholz et al. 2019). The contribution by Doane et al. (2019) outlines the importance of educating bystanders about the importance of supporting the target of bullying, whereas the study by Dal Cason et al. (2020) shows the role of moral courage to foster positive bystander behaviour. Finally, the study by Arënliu et al. (2019) highlights the usefulness of adapting anti-bullying intervention programs to lowincome countries.

Taken together, the six contributions provide several insights into bystander behaviour and are inspirational for future research in the field. Some important messages can be drawn based on the findings of the contributions included in this special issue. First, researchers need to take a multidimensional approach when investigating defending behaviour. Hence, the instruments currently adopted to detect defending should be revised in order to include items assessing constructive and destructive forms of defending. This could, in turn, contribute to elucidate the dynamics of offline and online bullying, and could help to design intervention programs aimed at fostering constructive bystander behaviour. 
Second, this special issue shows that combining neuroscience techniques with instruments adopted in the field of Social Sciences might greatly contribute to cyberbullying prevention and response. Future research might adopt such methodological innovation to explore various issues in connection with bystander behaviour of online and offline bullying.

Third, based on the contributions of this special issue, positive bystander behaviour is closely linked with moral variables (e.g., empathy; moral courage), which implies that prevention and intervention programs should include a socio-moral component. The possibility of including such a component can greatly help in tackling bullying, as fostering moral actions can act as a deterrent for various forms of aggression, including bullying. This indication is in line with the outcomes of intervention programs which aim primarily at fostering students' socio-cognitive abilities (i.e., ViSC program), and that have been shown in turn to empower bystanders to do something about the bullying they witness.

Acknowledgements I wish to express my gratitude to the Editors-inChief of the International Journal of Bullying Prevention, James O'Higgins Norman and Sameer Hinduja, for their kind invitation to serve as a Guest Editor for this special issue. I am very grateful to the Managing Editor, Mairéad Foody, for her help throughout the process of creating this special issue, and for her efforts in handling the peer review process. Many thanks to (in alphabetic order) Tijana Milosevic, Aikaterini Sargioti, and Robert Slonje, for reading an earlier draft of this editorial and providing their useful feedback. Finally, thank you to the researchers who contributed to this special issue.

\section{References}

Arënliu, A., Strohmeier, D., Konjufca, J., Yanagida, T., \& Burger, C. (2019). Empowering the peer group to prevent school bullying in Kosovo: Effectiveness of a short and ultra-short version of the ViSC social competence program. International Journal of Bullying Prevention. https://doi.org/10.1007/s42380-019-00052-4

Barhight, L. R., Hubbard, J. A., \& Hyde, C. T. (2013). Children's physiological and emotional reactions to witnessing bullying predict bystander intervention. Child Development, 84(1), 375-390. https:// doi.org/10.1111/j.1467-8624.2012.01839.x.

Barlinska, J., Szuster, A., \& Winiewski, M. (2018). Cyberbullying among adolescent bystanders: Role of affective versus cognitive empathy in increasing prosocial cyberbystander behavior. Frontiers in Psychology, 9(MAY), 1-13. https://doi.org/10.3389/fpsyg.2018.00799.

Bartlett, J. E., \& Bartlett, M. E. (2011). Workplace bullying: An integrative literature review. Advances in Developing Human Resources, 13(1), 69-84. https://doi.org/10.1177/1523422311410651.

Bastiaensens, S., Vandebosch, H., Poels, K., Van Cleemput, K., Desmet, A., \& De Bourdeaudhuij, I. (2014). Cyberbullying on social network sites. An experimental study into bystanders' behavioural intentions to help the victim or reinforce the bully. Computers in Human Behavior, 31(1), 259-271. https://doi.org/10.1016/j.chb.2013.10.036.

Dal Cason, D. Casini, A., \& Hellemans, C. (2020). Moral courage fostering bysyander intervention against workplace bullying: Findings from an exploratory study with a video-vignette procedure. International Journal of Bullying Prevention (in press).
DeSmet, A., Veldeman, C., Poels, K., Bastiaensens, S., Van Cleemput, K., Vandebosch, H., \& De Bourdeaudhuij, I. (2014). Determinants of selfreported bystander behavior in cyberbullying incidents amongst adolescents. Cyberpsychology, Behavior and Social Networking, 17(4), 207-215. https://doi.org/10.1089/cyber.2013.0027.

Doane, A. N., Ehlke, S., \& Kelley, M. L. (2019). Bystanders against cyberbullying: a video program for college students. International Journal of Bullying Prevention. https://doi.org/10.1007/s42380019-00051-5.

Hinduja, S., \& Patchin, J. W. (2015). Bullying beyond the schoolyard: Preventing and responding to cyberbullying (2nd edn.). Thousand Oaks: Sage Publications.

Kärnä, A., Voeten, M., Little, T. D., Poskiparta, E., Kaljonen, A., \& Salmivalli, C. (2011). A large-scale evaluation of the KiVa antibullying program: Grades 4-6. Child Development, 82(1), 311330. https://doi.org/10.1111/j.1467-8624.2010.01557.x.

Latané, B., \& Darley, J. M. (1970). The unresponsive bystander: Why doesn't he help? New York, NY: Appleton-Century-Crofts.

Lynn Hawkins, D., Pepler, D. J., \& Craig, W. M. (2001). Naturalistic observations of peer interventions in bullying. Social Development, 10(4), 512-527. https://doi.org/10.1111/1467-9507.00178.

Machackova, H., \& Pfetsch, J. (2016). Bystanders' responses to offline bullying and cyberbullying: The role of empathy and normative beliefs about aggression. Scandinavian Journal of Psychology, 57(2), 169-176. https://doi.org/10.1111/sjop.12277.

Monks, C. P., Smith, P. K., Naylor, P., Barter, C., Ireland, J. L., \& Coyne, I. (2009). Bullying in different contexts: Commonalities, differences and the role of theory. Aggression and Violent Behavior, 14(2), 146156. https://doi.org/10.1016/j.avb.2009.01.004.

Moxey, N., \& Bussey, K. (2019). Styles of bystander intervention in cyberbullying incidents. International Journal of Bullying Prevention. https://doi.org/10.1007/s42380-019-00039-1.

Obermaier, M., Fawzi, N., \& Koch, T. (2016). Bystanding or standing by? How the number of bystanders affects the intention to intervene in cyberbullying. New Media \& Society, 18(8), 1491-1507. https:// doi.org/10.1177/1461444814563519.

Ólafsson, R. F., \& Jóhannsdóttir, H. L. (2004). Coping with bullying in the workplace: The effect of gender, age and type of bullying. British Journal of Guidance and Counselling, 32(3), 319-333. https://doi. org/10.1080/03069880410001723549.

Paull, M., Omari, M., \& Standen, P. (2012). When is a bystander not a bystander? A typology of the roles of bystanders in workplace bullying. Asia Pacific Journal of Human Resources, 50(3), 351-366. https://doi.org/10.1111/j.1744-7941.2012.00027.x.

Rivers, I., Poteat, V. P., Noret, N., \& Ashurst, N. (2009). Observing bullying at school: The mental health implications of witness status. School Psychology Quarterly, 24(4), 211-223. https://doi.org/10. 1037/a0018164.

Romera, E. M., Bravo, A., Ortega-Ruiz, R., \& Veenstra, R. (2019). Differences in perceived popularity and social preference between bullying roles and class norms. PLoS One, 14(10), 1-14. https://doi. org/10.1371/journal.pone.0223499.

Rudnicki, K., Ouvrein, G., De Backer, C., \& Vandebosch, H. (2019). Intranasal oxytocin administration reduces bystanders' acceptance of online celebrity bashing. International Journal of Bullying Prevention. https://doi.org/10.1007/s42380-019-00054-2.

Salmivalli, C., Lagerspetz, K., Björkqvist, K., Österman, K., \& Kaukiainen, A. (1996). Bullying as a group process: Participant roles and their relations to social status within the group. Aggressive Behavior, 22(1), 1-15. https://doi.org/10.1002/(SICI) 1098-2337(1996)22:1<1::AID-AB1>3.0.CO;2-T.

Schultze-Krumbholz, A., Zagorscak, P., Hess, M., \& Scheithauer, H. (2019). The influence of school climate and empathy on cyberbystanders' intention to assist or defend in cyberbullying. International Journal of Bullying Prevention. https://doi.org/10. 1007/s42380-019-00040-8. 
Sivaraman, B., Nye, E., \& Bowes, L. (2019). School-based anti-bullying interventions for adolescents in low- and middle-income countries: A systematic review. Aggression and Violent Behavior, 45(April), 154-162. https://doi.org/10.1016/j.avb.2018.07.007.

Ttofi, M. M., \& Farrington, D. P. (2011). Effectiveness of school-based programs to reduce bullying: A systematic and meta-analytic review. Journal of Experimental Criminology, 7(1), 27-56. https:// doi.org/10.1007/s11292-010-9109-1.

Vandebosch, H., \& van Cleemput, K. (2009). Cyberbullying among youngsters: Profiles of bullies and victims. New Media \& Society, 11(8), 1349-1371. https://doi.org/10.1177/1461444809341263.
Varghese, M. E., \& Pistole, M. C. (2017). College student cyberbullying: Self-esteem, depression, loneliness, and attachment. Journal of College Counseling, 20(1), 7-21. https://doi.org/10.1002/jocc.12055.

Volk, A. A., Dane, A. V., \& Marini, Z. A. (2014). What is bullying? A theoretical redefinition. Developmental Review, 34(4), 327-343. https://doi.org/10.1016/j.dr.2014.09.001.

Yanagida, T., Strohmeier, D., \& Spiel, C. (2019). Dynamic change of aggressive behavior and victimization among adolescents: Effectiveness of the ViSC program. Journal of Clinical Child and Adolescent Psychology, 48(sup1), S90-S104. https://doi.org/10. 1080/15374416.2016.1233498. 